\title{
Hematological Changes in Severe $P$. falciparum Malaria
}

\section{Bidyut Prava Das $^{1 *}$, Ratnadeep Ganguly ${ }^{1}$, Hemant Kumar Khuntia ${ }^{2}$, Madhusmita Bal ${ }^{2}$ and Manoranjan Ranjit ${ }^{2}$}

\author{
${ }^{1}$ Department of Pathology, SCB Medical College and Hospital, Cuttack, India \\ ${ }^{2}$ ICMR-Regional Medical Research Centre, Chandrasekharpur, Bhubaneswar, India \\ *Corresponding author
}

\begin{tabular}{|c|c|}
\hline & A B S T R A C T \\
\hline & \multirow{7}{*}{ 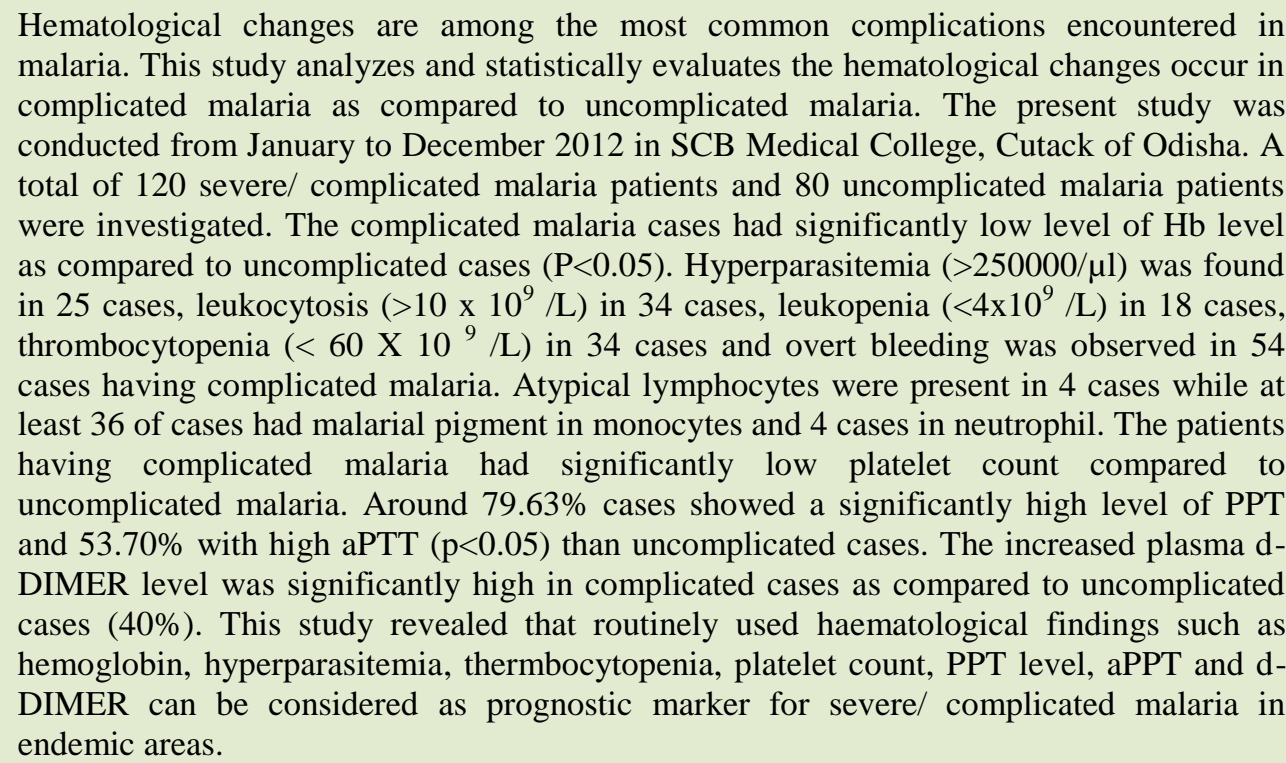 } \\
\hline Keywords & \\
\hline $\begin{array}{l}\text { Hematological, } \\
\text { P. falciparum, } \\
\text { Lymphocytes, } \\
\text { Complicated } \\
\text { malaria }\end{array}$ & \\
\hline Article Info & \\
\hline $\begin{array}{l}\text { Accepted: } \\
23 \text { May } 2017\end{array}$ & \\
\hline $\begin{array}{l}\text { Available Online: } \\
10 \text { June } 2017\end{array}$ & \\
\hline & \\
\hline
\end{tabular}

\section{Introduction}

Malaria continues to be a great health problem in some of the most populated areas of the world and continues to cause significant morbidity and mortality worldwide. As per World Malaria Report 2015, Southeast Asia region contributes to 10 percent of the global malaria burden and India contributes to 70 percent of the total malaria burden Southeast Asia region (WHO, 2015). Malaria is caused by protozoa parasite of the genus Plasmodium which infects and destroys red blood cells. Of the four species of plasmodia ( $P$. falciparum, $P$. malariae, $P$. ovale and $P$. vivax) infecting humans, $P$ falciparum is most lethal and clinically produces "mild" and "severe" manifestations (Ranjit et al., 2005). Most of the systemic complications of malaria results from hyperparasitemia involving multiple systems / organs- renal, hepatic cerebral, pulmonary and hematologic. The hematological abnormalities that have been reported to invariably accompany infection with malaria include anaemia, thrombocytopenia, 
splenomegaly, mild-to-moderate atypical lymphocytosis and infrequently disseminated intravascular coagulation (DIC) (Jairajpuri et al., 2014). In addition leucopenia, leucocytosis, neutropenia, neutrophilia, eosinophilia and monocytosis also have been reported by several authors (Murphy and Oldfeild, 1996; Jandel, 1996).

Hematological changes are considered as a hallmark of malaria (Ali et al., 2008 and Price et al., 2001). Prediction of the hematological changes enables the clinician to establish an effective and early therapeutic intervention in order to prevent the occurrence of major complications. These parameters are measurable indices of blood that serve as a marker for disease diagnosis (Petel et al., 2004). In this study, we have analyzed and statistically evaluated the hematological changes in cases of severe/complicated malaria admitted to a tertiary care hospital of Odisha, known to be highly endemic for malaria in India, with an aim to search for a prognostic marker to guide physicians to institute specific antimalarial treatment in an endemic situation like ours.

\section{Materials and Methods}

This observational study was conducted from August to October, 2012 in SCB Medical College, Cuttack a tertiary care hospital of Odisha, situated in the east coast region. The uncomplicated cases were recruited from subjects attending the OPD with acute febrile illness and found to be slide/ICT (OptiMAL) positive for $P$ falciparum infection. The complicated cases admitted in the IPD and found to be slide/ICT (OptiMAL) positive for $P$ falciparum infection were selected for the study. The detailed history of the patients including name, age, sex, date of admission, ward in hospitalized patients and OPD unit in outdoor patients were collected in a pretested questionnaire with reference to anaemia, jaundice, pupuric spots, level of consciousness (Glasgow coma scale), sign of meningeal irritation, focal neurologic deficits, hepatosplenomegaly and cardiovascular system. In follow up of the patients the following symptom were noted duration of unconsciousness, convulsion, renal failure, pulmonary oedema, hypoglycaemia, bleeding manifestation and outcome (recovery / death).

\section{Parasite Detection}

The diagnosis of malaria was established on peripheral blood film examination. Further samples were collected in (EDTA and citrated tubes as anticoagulant) for complete blood count (CBC) examination, ESR and prothrombin time (PT). Thick and thin blood films were prepared on glass slides from malaria patients of both the clinical groups and stained with Giemsa for detection and identification of $P$ falciparum, and for quantification of asexual parasitaemia (Hommel, 2002).

\section{Haematological investigation}

Complete haemograms (red blood cell count, total leukocyte count, total platelet count, haemoglobin level, etc.) were made by MS9 automatic haematology analyzer (MS Laboratory, France). The liver function test, renal function test and blod glucose level were estimated following standard laboratory methods using reagent kits (Ranbaxy [India] Ltd, New Delhi, India). The plasma sample was used to test the PT, aPTT and D-dimer level (semi quantitative) using reagent from Tulip diagnostics (P) Ltd, Goa, India

\section{Statistical analysis}

Data was analyzed by Graph pad prism. Unpaired student t test was $p$ value of $<0.05$ was taken as significant for all statistical analysis. Categorical data were compared using Pearson Chi-Square Test. 


\section{Results and Discussion}

A total number of 200 (complicated/severe: 120 and uncomplicated: 80) cases were enrolled in the study based on the inclusion and exclusion criteria. The frequency of clinical signs and symptoms of two study groups are depicted in table 1 . Out of 120 severe/complicated malaria cases with multiorgan failure admitted to the hospital, the major pernicious clinical manifestations were cerebral malaria (55\%), jaundice (53.3\%), overt bleeding (45\%), acute renal failure $(41.6 \%)$, convulsion $(38.3 \%)$ and severe anaemia (21.6\%) (Table 2). On analysis it was observed that the complicated malaria cases had significantly low level of $\mathrm{Hb}$ compared to uncomplicated cases $(\mathrm{P}<0.05)$, while a total of 86 cases $(71.67 \%)$ amongst the complicated cases had $\mathrm{Hb}$ level less than $100 \mathrm{~g} / \mathrm{L}$ and most of them (58/86) showed a serial decrease in $\mathrm{Hb}$ level during follow up and the lowest range recorded was $36 \mathrm{~g} / \mathrm{L}$. Majority of anaemia cases showed a microcytic and hypochromic blood picture (68.6\%) followed by normocytosis and normochromia (23.26\%) and mortality rate was higher in the group having $\mathrm{Hb}<50 \mathrm{~g} / \mathrm{L}$. Microscopic examination of WBC revealed atypical lymphocyte in 4 cases, eosinophilia in 3 cases and basophilia in 2 cases.

The highest leucocyte $\left(>10 \times 10^{9} / \mathrm{L}\right)$ count was recorded $28.3 \%$ of complicated malaria cases and the range of leucocyte varies from $24 \mathrm{X} 10^{9} / \mathrm{L}$ to $2.5 \times 10^{9} / \mathrm{L}$, while $61.67 \%$ patients showed thrombocytopenia $<100 \mathrm{X}$ $10^{9} / \mathrm{L}$ in $28.33 \%$ of severe malaria cases $\left(<60 \times 10^{9} / \mathrm{L}\right)$. Hyperparasitemia was found in 25 cases out of 120 complicated cases and $84 \%$ of them died during follow-up. Further it has been observed that at least $30 \%(n=36)$ of cases had malarial pigment in monocytes and $3.33 \% \quad(n=4)$ cases in neutrophil. The prognostic significance of the leukocyte parameters have been shown in table 3 .
Overt bleeding was observed in $45 \%$ of subjects having complicated malaria. The patients having complicated malaria have significantly $(p<0.05)$ lower platelet count as compared to uncomplicated malaria. The type of presentation found in the patients having overt bleeding were sub conjunctival haemorrhage $(16.67 \%)$, GI bleed $(15 \%)$, epistaxis $(11.67 \%)$ and intracranial bleed $(10 \%)$. The subjects (54) having overt bleeding when subjected to other coagulation assay, it was found that $79.63 \%$ had elevated level of PT which was significantly higher $(\mathrm{p}<0.05)$ than uncomplicated cases. Similar to PT, aPTT was deranged in $53.70 \%$ of complicated cases, which was also significantly higher than the uncomplicated cases $(\mathrm{p}<0.05)$. Further there was a significant $(\mathrm{p}<0.05)$ prolongation in bleeding time $(5.29$ $\pm 1.48 \mathrm{~min})$ and clotting time $(8.25 \pm 1.42 \mathrm{~min})$ in complicated malaria cases than the uncomplicated cases (BT: $2.55 \pm 0.93$ and CT $\pm 6.24 \pm 0.89$ ). Occurrence of disseminated intravascular coagulation (DIC) was observed in $74.7 \%$ of patients presenting with low platelet count, prolonged PT, elevated aPTT and elevated fibrin-degradation products (FDP) or d-DIMER (an indication of in vivo fibrin deposition and degradation). Among these cases the level of d-DIMER was $800-$ $3200 \mathrm{ng} / \mathrm{ml}$ in 10 patients and $>3200 \mathrm{ng} / \mathrm{ml}$ in 3 patients. Out of 10 patients 7 patients were died during treatment who had d-DIMER was $800-3200 \mathrm{ng} / \mathrm{ml}$ and 3 out 3 died who had dDIMER >3200 ng/ml. The increased plasma d-DIMER level was significantly high in complicated cases compared to uncomplicated cases $(40 \%)$. The prognostic significance of the coagulation parameters have been shown in table 4 .

Malaria is a major health problem in the tropical and temperate regions of the world which poses a significant burden on health expenditure. Prompt and accurate diagnosis is critical towards the effective management of 
malaria. Development of effective diagnostic strategies not only helps resource-limited areas but also developed countries, where malaria diagnostic expertise is often lacking (Bell et al., 2005 and Reyburn et al., 2007).

Table.1 Laboratory and clinical characteristics of complicated and uncomplicated patients

\begin{tabular}{|c|c|c|c|}
\hline & $\begin{array}{c}\text { Uncomplicated } \\
(\mathbf{n}=\mathbf{8 0})\end{array}$ & $\begin{array}{c}\text { Complicated } \\
(\mathbf{n}=120)\end{array}$ & $\begin{array}{c}\mathbf{P} \\
\text { value }\end{array}$ \\
\hline Median Age (Years) & 29.5 & 33.0 & NS \\
\hline $\begin{array}{l}\text { Geometric mean of } P \text {. falciparum } \\
\text { density }(95 \% \mathrm{CI})\end{array}$ & $\begin{array}{c}2687 \\
(1985-3322)\end{array}$ & $\begin{array}{c}39879 \\
(25651-39879)\end{array}$ & $<0.01$ \\
\hline Temperature $\left({ }^{\circ} \mathrm{C}\right)$ & $38.4 \pm 0.4$ & $38.7 \pm 0.6$ & NS \\
\hline Hepatomegaly (n) & 0 & 59 & $<0.01$ \\
\hline Splenomegaly(n) & 9 & 78 & $<0.01$ \\
\hline Pallor (n) & 27 & 79 & $<0.01$ \\
\hline Haemoglobin $(\mathrm{g} / \mathrm{dl})^{\mathrm{a}}$ & $9.90 \pm 1.64$ & $8.50 \pm 2.82$ & $<0.01$ \\
\hline Total leukocyte count $(\mathrm{m} / \mathrm{mm} 3)^{a}$ & $5.4 \pm 2.3$ & $9.9 \pm 5.8$ & $<0.05$ \\
\hline Total platelet count $(\mathrm{m} / \mathrm{mm} 3)^{a}$ & $208.1 \pm 4.7$ & $101.7 \pm 7.7$ & $<0.05$ \\
\hline Biluribin $(\mathrm{mg} / \mathrm{dl})^{\mathrm{a}}$ & $1.1 \pm 0.8$ & $12.8 \pm 11.52$ & $<0.05$ \\
\hline Aspartate transferase $(\mathrm{IU} / \mathrm{L})^{\mathrm{a}}$ & $37 \pm 10.5$ & $162.9 \pm 111.4$ & $<0.05$ \\
\hline Alanine transferase (IU/L) ${ }^{a}$ & $27 \pm 9.4$ & $111 \pm 49.6$ & $<0.05$ \\
\hline Alkaline phophatase $(\mathrm{IU} / \mathrm{L})^{\mathrm{a}}$ & $166.0 \pm 20.9$ & $167.6 \pm 86.1$ & NS \\
\hline Serum urea $(\mathrm{mg} / \mathrm{dl})^{\mathrm{a}}$ & $34.2 \pm 5.2$ & $116.8 \pm 66.3$ & $<0.05$ \\
\hline $\begin{array}{l}\text { Serum creatinine } \\
(\mathrm{mg} / \mathrm{dl})^{\mathrm{a}}\end{array}$ & $0.7 \pm 0.6$ & $4.2 \pm 2.9$ & $<0.05$ \\
\hline Fasting Sugar $(\mathrm{mg} / \mathrm{dl})^{\mathrm{a}}$ & $84.2 \pm 11.3$ & $61.3 \pm 19.6$ & $<0.05$ \\
\hline
\end{tabular}

NS: not significant

${ }^{\mathrm{a}}:$ Mean \pm SD

Table.2 Pernicious manifestations in malaria with multi organ failure

\begin{tabular}{|l|c|c|}
\hline Manifestations & $\begin{array}{c}\text { No of } \\
\text { Cases }\end{array}$ & $\begin{array}{c}\text { Percentage } \\
(\%)\end{array}$ \\
\hline Cerebral malaria $(<9)$ & 66 & 55.0 \\
\hline Jaundice & 64 & 53.3 \\
\hline Bleeding & 54 & 45.0 \\
\hline Renal failure & 50 & 41.7 \\
\hline Convulsion & 46 & 38.3 \\
\hline Severe anaemia $(\mathrm{Hb}<5 \mathrm{~g} / \mathrm{dl})$ & 26 & 21.7 \\
\hline ARDS & 8 & 6.6 \\
\hline Hypotension & 4 & 3.3 \\
\hline Hypoglycemia & 4 & 3.3 \\
\hline
\end{tabular}


Table.3 Prognostic significance of leukocyte parameters and hyperparasitaemia

\begin{tabular}{|l|l|l|l|}
\hline Leukocyte Parameter & Cases & $\begin{array}{l}\text { No of } \\
\text { Death }\end{array}$ & $\begin{array}{l}\% \text { of } \\
\text { mortality }\end{array}$ \\
\hline Neutropenia & 16 & 10 & 62.50 \\
\hline Neutrophilia with left shift & 22 & 15 & 68.18 \\
\hline Neutrophil containing pigments & 4 & 3 & 75.00 \\
\hline $\begin{array}{l}\text { Complicated Pf cases without } \\
\text { leukocyte manifestations }\end{array}$ & 82 & 29 & 35.37 \\
\hline Parasites $>250000 / \mu 1$ & 25 & 21 & 84.00 \\
\hline Parasites $<250000 / \mu 1$ & 95 & 33 & 34.73 \\
\hline
\end{tabular}

Table.4 Prognostic significance of coagulation parameters

\begin{tabular}{|l|l|l|l|}
\hline Coagulation Parameter & Cases & $\begin{array}{l}\text { No of } \\
\text { Death }\end{array}$ & $\begin{array}{l}\% \text { of } \\
\text { mortality }\end{array}$ \\
\hline Thrombocytopenia $\left(<60 \times 10^{9} / \mathrm{L}\right)$ & 34 & 24 & 70.59 \\
\hline $\begin{array}{l}\text { Prolonged PT } \\
(>1 \text { sec of control) }\end{array}$ & 43 & 27 & 62.79 \\
\hline $\begin{array}{l}\text { Raised aPTT } \\
(>40 \text { sec) }\end{array}$ & 29 & 19 & 65.52 \\
\hline $\begin{array}{l}\text { Elevated d-DIMER } \\
(>200 \text { ng/ml })\end{array}$ & 40 & 25 & 62.50 \\
\hline $\begin{array}{l}\text { Complicated cases without } \\
\text { coagulopathy / bleeding }\end{array}$ & 66 & 9 & 13.3 \\
\hline
\end{tabular}

In the current study, amongst the complicated malaria cases $55 \%$ had exhibited cerebral malaria and jaundice followed by bleeding, renal failure and convulsion. Different types of bleeding manifestation were observed in the patients and mortality was higher in the group having severe anaemia. The pathogenesis of anaemia in malaria is particularly complex and incompletely understood. It is thought to result from a combination of haemolysis of parasitized red blood cells; accelerated removal of both parasitized and innocently un-parasitized red blood cell, depressed as well as ineffective erythropoiesis with dyserythropoietic changes and anaemia of chronic disease (Angus, 1999). In the present study complicated cases of malaria cases showed a statistically significant lower of $\mathrm{Hb}$ level as compared to uncomplicated cases. The prevalence of high parasitemia load present in complicated cases lead to high rate of mortality in this group. A lowering of platelet count was observed in $P$. falciparum cases and significantly lowers in complicated cases than uncomplicated cases. A variety of haematological alterations like progressively increasing anaemia, thrombocytopenia, leukocytosis or leukopenia have been reported in cases of malaria (Koltas et al., 2007).

The possible mechanisms leading to thrombocytopenia in malaria can be immune mechanisms, oxidative stress, alterations in splenic functions and a direct interaction between plasmodium and platelets. The mechanism which might be a causative factor for thrombocytopenia in $P$. falciparum and $P$. vivax infection could be peripheral destruction, induced by $P$. falciparum, in 
which immune complexes generated by malarial antigens lead to sequestration of the injured platelets by macrophages in the spleen. And thus, prediction of the haematological changes enables the clinician to establish an effective and early therapeutic intervention in order to prevent the occurrence of major complications. The evaluation of prothrombin time in cases having overt bleeding showed elevated PT and that is also significantly high in complicated cases as compared to uncomplicated cases. Same type of observation was also observed in case of aPTT in control and cases. A high percentage of individuals in complicated cases showed high level of d-DIMER level which is significantly different from uncomplicated cases. The suggested mechanism of thrombocytopenia may be through peripheral destruction and excessive removal of platelets by splenic pooling as well as platelet consumption by the process of disseminated intravascular coagulation (DIC) (Maina et al., 2010). The prognostic significance of all these coagulation parameter was observed in complicated malaria cases as the percentage of mortality was high in these groups as compared to complicated malaria cases without coagulopathy.

Overall, the haematological aspects of malaria constitute a very interesting area. We have observed a significant correlation in haematological changes such as anaemia, thrombocytopenia and leucopoenia with complicated malarial infection. When used in combination with other clinical and microscopy methods, these parameters could improve malaria diagnosis and treatment. Prediction of the haematological changes would enable the clinician to establish an effective and early therapeutic intervention in order to prevent the occurrence of major complications.

\section{Acknowledgement}

The authors are thankful to Prof Sidhartha Dash, Principal SCB Medical College, Cuttack for constant encouragement, Prof B N Das, former Professor Department of Medicine and Prof B N Mohaptra, former Associate Professor, Department of Medicine SCB Medical College, Cuttack for patient selection and patient care. The authors also acknowledge Dr SK Kar former Director, RMRC, Bhubaneswar, for providing necessary laboratory facilities for the study. We acknowledge the patients for their consent to participate in the study. The authors also pay deep homage to the patients who have left for heavenly abode but left the blood samples for developing strategy for future patient care.

\section{References}

Ali, H.A., Abdulla, M.U., Nadeem, J.Y., Ahmed, S.A., Dujana, Al.H., Ahmed, A.S. 2008. Malaria and Hematological changes, Pak. J. Med. Sci., 24: 287291.

Angus, B.J., Chotivanich, K., Silamut, K., Ruangveerayuth, R., Hardeman, M.R. 1999. Red blood cell deformability as a predictor of anemia in severe Falciparum malaria, Am. J. Trop. Med. Hyg; 60:733-737.

Bell, D.R., Jorgensen, P., Christophel, E.M., Palmer, K.L. 2005. Malaria risk: estimation of the malaria burden. Nature; 437(7056): E3-E4, discussion E4-E5.

Hommel, M. 2002. Diagnostic Methods in Malaria. In: Warrell DA, Gilles HM (eds.), Essential Malariology, $4^{\text {th }}$ edition. London, Arnold, p. 35-58.

Jairajpuri, Z.S., Rana, S., Hassan, M.J., Nabi, F., Jetley, S. 2014. An Analysis of Hematological Parameters as a Diagnostic test for Malaria in Patients with Acute Febrile Illness: An 
Institutional Experience, Oman. Med. J., 29(1): 12-17.

Jandle, J. 1996. Hemolytic anemias caused by infection of red blood cells. In: Blood. 2nd edition. New York: Little brown and company, 473-501.

Koltas, I.S., Demirhindi, H., Hazar, S., Ozcan, K. 2007. Supportive presumptive diagnosis of Plasmodium vivax malaria. Thrombocytopenia and red cell distribution width, Saudi. Med. J., 28(4): 535-539.

Maina, R.N., Walsh, D., Gaddy, C., Hongo, G., Waitumbi, J., Otieno, L., et al., 2010. Impact of Plasmodium falciparum infection on haematological parameters in children living in Western Kenya. Malar. J., 9(Suppl 3):S4.

Murphy, G.S., and Oldfeild, E.C. 1996. Falciparum malaria, Inf. Dis. Clin. North. Am., 10:747-75.

Petel, U., Gandhi, G., Friedman, S. 2004. Thrombocytopenia in plasmodium malaria, Am. J. Trop. Med. Hyg., 59:
859-865.

Price, R.N., Simpson, J.A., Nosten, F., Luxemburger, C., Hkirjaroen, L., Ter Kuile, F., et al., 2001. Factors contributing to anemia after uncomplicated falciparum malaria. Am. J.Trop. Med. Hyg., 65(5):614622.

Ranjit, M.R., Das, A., Das, B.P., Das, B.N., Dash B.P, Chhotray GP. 2005. Distribution of Plasmodium falciparum genotypes in clinically mild and severe malaria cases in Orissa, India. Trans. R. Soc. Trop. Med.Hyg., 99(5):389-395.

Reyburn, H., Mbakilwa, H., Mwangi, R., Mwerinde, O., Olomi, R., Drakeley, C., et al., 2007. Rapid diagnostic tests compared with malaria microscopy for guiding outpatient treatment of febrile illness in Tanzania: randomised trial, Bio. Med. J., 334(7590):403.

WHO. 2015. World Malaria Report 2015 Geneva: World Health Organization.

\section{How to cite this article:}

Bidyut Prava Das, Ratnadeep Ganguly, Hemant Kumar Khuntia, Madhusmita Bal and Manoranjan Ranjit. 2017. Hematological Changes in Severe P. falciparum Malaria. Int.J.Curr.Microbiol.App.Sci. 6(6): 1733-1739. doi: https://doi.org/10.20546/ijcmas.2017.606.201 